\title{
Models of Applications for the ICT Transformation in Classroom Education Paradigm
}

\author{
Mervin T. Hutabarat ${ }^{1}$, Yani Widyani ${ }^{2}$, Armein Z. R. Langi ${ }^{3}$ \\ School of Electrical Engineering and Informatics, \\ Institut Teknologi Bandung, Jalan Ganesha 10 Bandung 40132, Indonesia \\ ${ }^{1}$ mhutabar@stei.itb.ac.id, ${ }^{2}$ yani@informatika.org, ${ }^{3}$ langi@ieee.org
}

\begin{abstract}
A study report of the UNESCO anticipates the changes in the education paradigm with the use of ICT. Contrary to the current education paradigm where students receive classroom instruction and study individually outside classroom, ICT supported educational paradigm will lead student to undergo individual learning according to their abilities and achievements. Students will also learn more in a collaborative work outside the classroom. However, these changes will be difficult to be fulfilled if they requires drastic changes in the way teachers work. Therefore, there is a need for a guided process which empowers teacher to evolve from the old to the new education paradigm. The process will use ICT applications to help the teachers. Initially teachers will develop and implement appropriate lesson plans according to the current paradigm. Then the application will lead the teachers to prepare materials for students to learn independently instead of classroom teaching. This paper proposes model applications required for such changes. It discusses the requirements for each application and major changes in version for guiding the transformation processes.
\end{abstract}

Index Terms - e-Education Applications, Classroom technology, Collaborative Learning.

\section{Introduction}

ICT has generally been accepted as a technology that could lead to a paradigm shift in education [1]. Figure 1 summarizes such paradigm shift. The shifts include the change from classroom to individual learning and teacher as knowledge provider to learning facilitator. As an anticipation of the transformation, UNESCO has published a range of documents on this subject intended for governments in preparing their education policy [2]. The details of how to realize changes for the transformation will not be different from one country to another. They will depend on many things, i.e. cultural and education system.

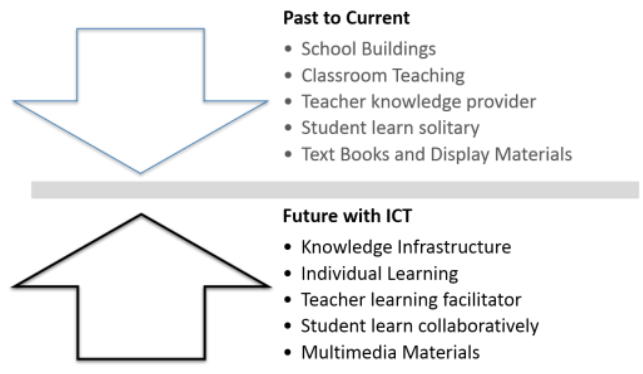

Fig. 1 ICT-enabled Education Paradigm Shift

There are efforts to develop standards for the eLearning technology such as in [3]. Other researchers develop the e-Learning system by integrating currently available technologies despite they are not specifically designed for education [4]. Other experts believe that it will be difficult to develop unified tools for the e-Learning [5]. Besides, such technology developments are often treated as if the lesson development is a separate entity from the tools or applications. Information Technology experts also focus more on application for the learning management. Less effort are spent on technology for learning design even though good learning process is a key factor for the students to succeed. Furthermore, teachers are expected to develop content using this technology. Thus, teachers have to face both the pedagogic and technological issues when preparing a lesson which may hamper them to be productive.

Efficacious use of ICT in education must support student-centered and collaborative learning in the learning process. Student-centered and collaborative learning are also important issues for which a Lesson Study (LS) is conducted [6]. Such a practice can also be utilized for the content development. The digital and internet supported lesson study, called Digital Learning Lesson Study (DLLS) [7], will be good starting point of developing requirement for the applications as the content development.

We propose a model of applications taking into account the above issues. Our model pays attention on how to provide applications that enable teachers to develop content for the digital learning collaboratively. The application would also cater the change of education paradigm from classroom to individual learning.

\section{Student-Centered Learning and the Lesson Study}

In the e-education, the focus of learning activities must be on the learners or the students. Thus, during the content development, student interest must be put first. A Lesson Study can be an alternative tool to do so. In a lesson study teachers in a community gather to discuss and plan a lesson.

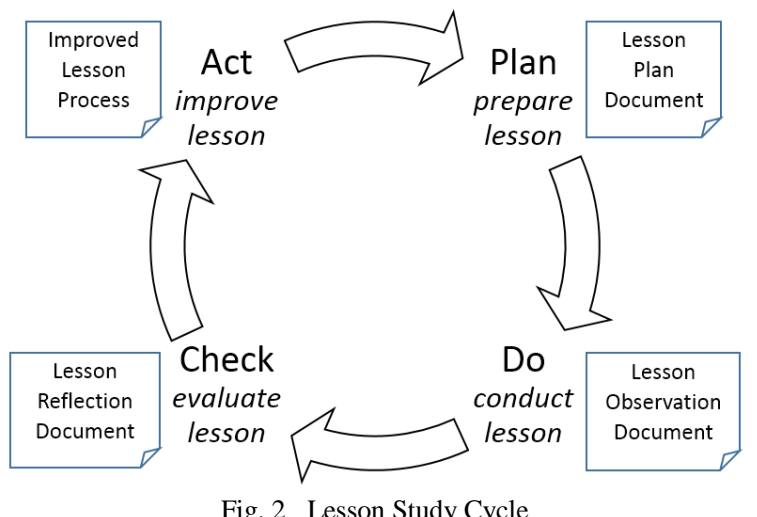

Fig. 2 Lesson Study Cycle 
Figure 2 shows a lesson study cycle in change management Plan, Do, Check, and Act (PDCA) cycle. In the first cycle, the Plan, the community selects a topic from the curriculum. Each of the community members prepares a Preliminary Lesson Plan. The community then chooses one of the Lesson Plans to be discussed and perfected. After finishing and writing the final Lesson Plan, the members of the community then select one of its members to be a model teacher to perform the Lesson Plan in a real classroom teaching and learning activity.

In the second stage, the Do, the model teacher then performs the Lesson Plan in an open lesson. During the lesson, other members of the community observe how the lecture is conducted and how the students react to the lesson. The observation is done in detail to the actual students' words and behavior in a Lesson Script.

The lesson is also recorded in a video so that additional reflection can be easily done after the lesson finishes. Two video recorders are needed to record the teacher and the students.

The third stage, the Check, is a Post Lesson Conference (PLC). Members of the community organize a reflection on the lesson. Each of the members presents their observations. The community then discusses Lesson Script based on the observation. The discussion is focused on how the students learn, i.e. how they relate in a lesson, what entice or obstruct them to learn, and what inspire them to get into the knowledge. Video recording of the lesson may be played to recollect what happened in the lesson. In this stage a mind mapping or concept mapping in a Blackboard Documentation will benefit the members to get a structured view on how the students learn, and finally the concept on how student study and compose thoughts.

The fourth stage is the Act. In this stage the knowledge gathered from the previous stages is synthesized into an improved learning process for students. The result is a document of learning process which explicitly describes how students learn the topics. It covers all identified possibilities on how the topic is taught and how students respond.

As shown in Fig. 2 a lesson study requires the members to prepare related documents. Such documentation is strongly required in order to convert the knowledge developed through the process from being tacit to be explicit. Thus, the lesson study is a potential routine to be adapted in a Learning Design for e-Learning content development.

\section{Adopting DLLS for e-Learning Learning Design Process}

In the original version of Lesson Study, community members must meet regularly in a certain place. Therefore, members of the community must come from a close area among others so that they should not spend too much time and money for traveling. A digital version of Lesson Study, namely Digital Learning Lesson Study (DLLS) [7] reduces the need to meet physically by running the meeting virtually online. Part of the lesson study stages are run online, i.e. the $\mathrm{P}, \mathrm{C}$, and T stages. A specific application is set up for the DLLS. Figure 3 shows a digital empowered LS cycle.

In a DLLS, most of the discussion and conference activity are replaced by a discussion forum, both synchronous and asynchronous. Special editors are provided for writing and editing the Lesson Plan and for recording the Lesson Script for the Lesson Observation. The editors are dedicated web based text editors.

The lesson run in the DLLS is conducted in two seperated classrooms. In the first classroom the students learn directly with the teacher while in the other classroom students receive instructions through a video streaming. The lesson in the second classroom simulates how students learn in a virtual world.

The Lesson Plan must cover all important issues as prescribed by the curricula. It deliberates the students as learners, topic to learn and the learning objectives, and the means to convey the lesson. Therefore, Learning Design describes in [4] which Target Specification, Competencies definition, and Learners' Profiling are included in the Lesson Plan.

The Digital Learning Lesson Study is a detailed elaboration scheme to study how students learn. It provides a good routine for a student-centered lesson research. It offers a scheme where education and technology experts can work together for a learning design process in the early phase of the life cycle of the e-Learning process previously less deliberated.

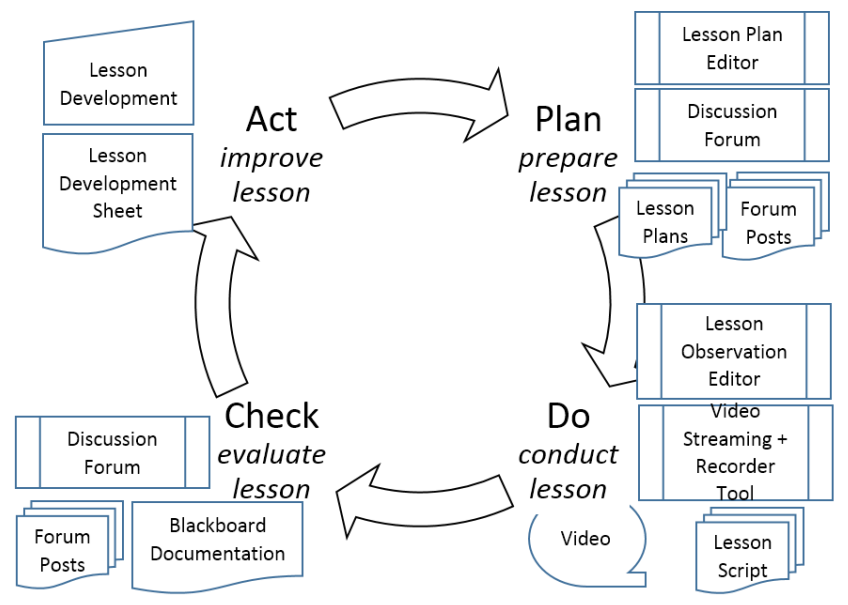

Fig. 3 Digital Learning Lesson Study Cycle

Most of the teachers can be assumed to be fully prepared to teach in a classroom but not through a virtual presence. Here, members of the lesson study community should in early stage always be reminded that the final aim of the process is e-Learning process. Thus, they will spend more time thinking on how students can learn in a virtual world. Running a virtual class provides the teacher an experience on how to get student engaged in learning without their physical presence.

Several adaptations of the DLLS are necessary in order to get its advantage in the learning design process. The Lesson Plan and Lesson Observation editors must guide teachers or lesson researchers to write a lesson plan with more interactions with other students and multimedia materials than the teacher. Video recording of student interactions must be split in small clips to ease to elaborate fragments on how students learn.

Adoption of the DLLS for the e-Learning Design Process must be in-line with the life cycle of the e-Learning process. This life cycle is described in [3] as Learning 
Design, Learning Production, Learning Deployment, and Learning Assessment as shown in Fig. 4.
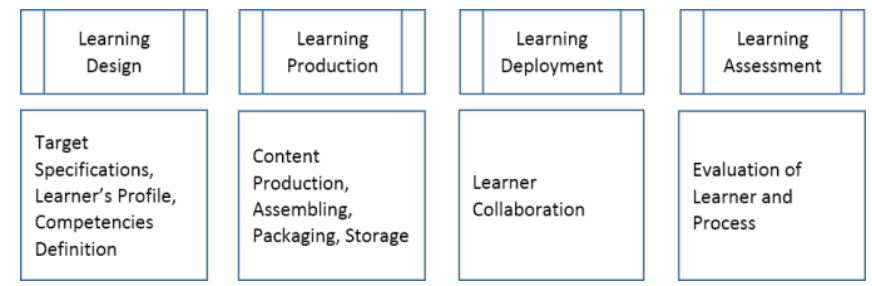

Fig. 4 e-Learning Process Life Cycle Adapted from [3]

\section{Required Applications and Development Phases}

The above elaboration of the DLLS and the requirements for its adoption in the e-Learning Learning Design Process indicate the required application to support the process. At least there should be one application for each of the lesson study cycle. In addition, there should be a portal to ease accesses to each of the applications and there should be a data base system to manage the large data collected through the process.

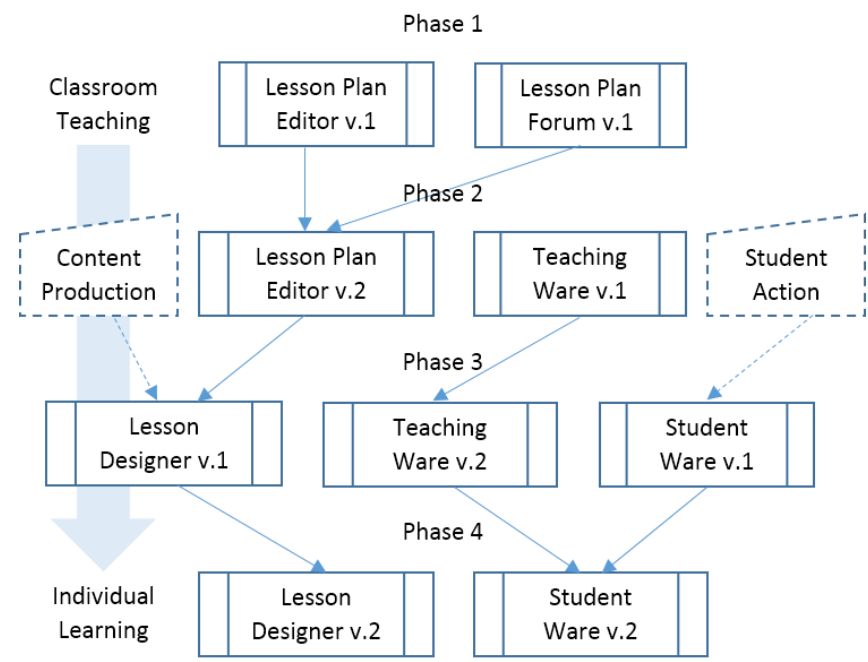

Fig. 5 Lesson Preparation and Deployment Applications

The development phases of the required applications take into consideration the Lesson Study Cycle, e-Learning Life Cycle, concurrent design of learning process, and application for the learning design. With these considerations, the development phases of the applications can be assembled into two major application groups, namely the lesson preparation and deployment applications and lesson improvement and development applications. The earlier group of applications is shown in Fig. 5. It combines the Plan and Do stages in the Lesson Study Cycle and the Learning Design, Learning Production, and Learning Deployment in the e-Learning Process Life Cycle. The second groups of applications as shown in Fig. 6 combines the Do, Check, and Act stages of the LS cycle and the Learning Design of the e-Learning process life cycle. There is at least three phases of developments. Both groups of applications merge at the fourth phase to produce an integrated application for the lesson development.

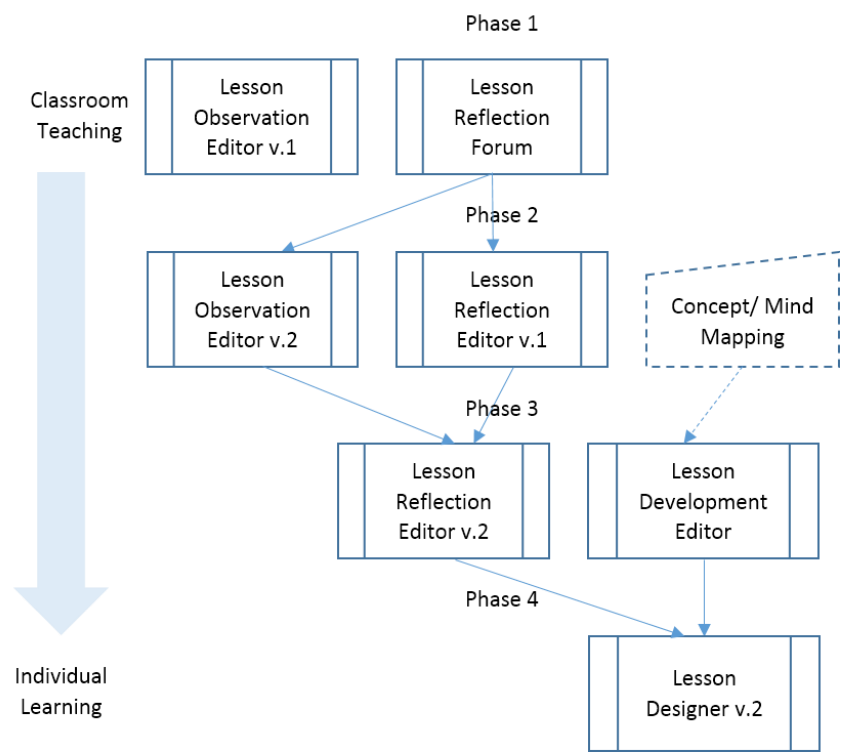

Fig. 6 Lesson Improvement and Development Applications

\section{Essential Application Functions and Features}

The followings are essential functions and features of the main applications described above.

\section{A. Lesson Plan Editors}

The Lesson Plan Editor functions as the editor for Lesson Plans. The Lesson Plan must take into account curricula requirements. Therefore, in order to simplify the Lesson Plan editing, the editor should have features of providing a connection to the curricula. The editor should easily incorporate these requirements through a menu and an active suggestion windows.

The later version of the Lesson Plan Editor must also have a groupware function. It enables members of the community to work on the same Lesson Plan. The application must have user privilege control for editing authorization. It must keep versions of the edited documents. The discussion forum for the Lesson Plan editing is embedded to the Lesson Plan Editor. Member activities in editing the Lesson Plan should be recorded to records the contribution of the members. This application should be designed as a web application.

\section{B. Teaching Ware}

The main function of the Teaching Ware is to provide teacher an easy access of reading and running a lesson in a classroom. This application is run on tablet computers, phablets or other handheld devices. The application displays a lesson scenario as prescribed by the Lesson Plan Editor. It shows the step-by-step activities to be done by the students in the classroom. It prompts the teacher what to do during the lesson. The earlier version may have the elapse time display and an indicator to show the level of importance of the student tasks.

The later function of the Teaching Ware is to provide access and control to other classroom tools such as classroom server and video player or display computer. Teacher or lecturer manages the classroom activity, i.e. when to run animations or videos, and when to display student worksheets and exercises, via the application. 


\section{Student Ware}

The Student Ware runs on tablets or netbook computers. It directs the student to the learning activities in the lesson. Lesson materials are stored in the server. Student access to these materials is done through an internet browser included in the Student Ware. The browser and its access control are customized only to the lesson activity so that students will not be distracted to access other than the lesson.

The earlier features of the Student Ware must include web browser, play HTML5 animations and videos. The later version should be able to communicate with the later version of the Teaching Ware enabling teacher to monitor the student activities.

\section{Lesson Observation Editor}

The Lesson Observation Editor is a web application for writing the Lesson Scripts. The editor must access them through an access and authorization control mechanism. The application provides the observers with a simple text editor. Each of the entries is treated as separate entities. In addition to a short title, each entity must also have key words. A feature for suggesting related key words provided by the application.

\section{E. Lesson Reflection Editor}

The reflection editor is an application to replace a discussion forum. The earlier version supports thread connections and thread comparisons for the community to decide and select issues to be discussed more and which issues are considered to be subtle. The later version is combined with the observation editor. It provide a feature to present connections among discussed threads with the Lesson Script through the key words.

\section{F. Lesson Development Editor}

The lesson Development Editor functions as a tool for teachers or lesson researcher to document how students study certain topics. It must support concept or mind mapping capabilities.

\section{G. Lesson Designer}

The main functions of the Lesson Designers is to ease teacher to write Lesson Plan and prepare the necessary bits and parts, such as animations and exercises, and arrange and manage all the stuff into the Learning Management System (LMS). The earlier version of the Lesson Designer should have all the functions of the Lesson Plan Editor and interfaces to external productivity and content production tools. It should be able to convert files with different format to its own selected standard formats.s

The later version of the Lesson Designer is an integration of the earlier version, Lesson Reflection Editors and the Lesson Development Editors. Thus, it must have all functions and features combined applications.

\section{Conclusion}

This paper has presented alternative processes and their correlated applications to a lesson development as part of eLearning Learning Design process. It enables the teachers as lesson researchers to migrate from developing a lesson for a classroom teaching to student individual learning as anticipated from the use of ICT in education.

\section{Acknowledgment}

The authors would like to thank the Directorate of Research and Community Service of the Ministry Education for the support funding toward this research through the Rapid Program.

\section{References}

[1] W. D. Haddad and A. Draxler, Technologies for Education: Potential, Parameters, and Prospects, Paris: UNESCO, 2002.

[2] J. Anderson, ICT Transforming Education: A Regional Guide, Bangkok: UNESCO, 2010

[3] I. Varlamis and I. Apostolakis, "The present and future of standards for e-learning technologies," International Journal of Knowledge and Learning Objects, vol. 2, pp. 59-76, 2006.

[4] M. Relvas, "e-learning in the classroom?" Conferencia Internacional ecoMedia-europe, May 2012

[5] E. Voiyatzaki, S. Papadakis, and E. Rossiou, "One size does not fit all: A case study of combining networked learning methods and tools," Proceedings of the $6^{\text {th }}$ International Conference on Networked Learning, pp. 847-848, May 2008.

[6] H. Kuno, "Conceptualizing Lesson Study", International ScientificallyPractical Conference: Teacher Professional Development: Traditions and Changes (report book), 4-12.

[7] Y. Bandung, A. Z. R. Langi, and M. T. Hutabarat, "Digital learning lesson study (dl-ls) for teacher learning community, "Proceeding of the Joint International Conference on Rural Information and Communication Technology and Electric-Vehicle Technology, pp. 1-5, Nov. 2013 